\title{
Pathophysiology and treatment of Cheyne-Stokes respiration
}

\author{
M T Naughton
}

Cheyne-Stokes respiration is a disorder characterised by recurrent central apnoeas during sleep alternating with a crescendo-decrescendo pattern of tidal volume. ${ }^{12}$ It is often observed in patients with congestive heart failure, usually during stages 1 and 2 non-REM sleep when ventilation is under chemical-metabolic control. ${ }^{2}$ Patients with Cheyne-Stokes respiration usually present with the symptoms of orthopnoea, paroxysmal nocturnal dyspnoea, excessive daytime sleepiness and witnessed apnoeas in the setting of congestive heart failure. ${ }^{13}$ Excessive weight and snoring may be absent. Approximately $50 \%$ of patients with symptomatic congestive heart failure have sleep apnoea, mainly of the Cheyne-Stokes respiration variety. ${ }^{4-6}$ As congestive heart failure occurs in $1 \%$ of the adult population and doubles in prevalence for each decade beyond 60 years, ${ }^{7}$ Cheyne-Stokes respiration is common but often left unrecognised.

\section{Adverse effects}

Based upon small case series, patients with congestive heart failure and Cheyne-Stokes respiration have a significantly greater mortality, ${ }^{89}$ particularly if present during wakefulness, ${ }^{10}$ than those without CheyneStokes respiration. Although Cheyne-Stokes respiration is likely to arise as a result of congestive heart failure, once present it is likely to have adverse effects upon cardiac function akin to a vicious cycle. Following an initial cardiac insult there is a compensatory increase in sympathetic activity ${ }^{11}{ }^{12}$ which in susceptible patients causes hyperventilation, ${ }^{13}$ destabilises respiratory control, and leads to CheyneStokes respiration. Once Cheyne-Stokes respiration is established, apnoea related hypoxaemia causes cardiac diastolic dysfunction. ${ }^{14}$ Hypoxaemia and arousals lead to further increases in sympathetic activity ${ }^{15}$ which contribute to potentially fatal arrhythmias ${ }^{16-18}$ and further cardiotoxicity. ${ }^{19}$

Hyperventilation and resultant increased work of the respiratory muscles probably play a part in the symptom of paroxysmal nocturnal dyspnoea $^{1}$ and place an increased demand upon the already reduced cardiac output. ${ }^{20}$

Finally, patients with congestive heart failure and Cheyne-Stokes respiration frequently complain of fatigue and excessive daytime sleepiness which relate to reduced amounts of total, slow wave, and REM sleep in association with marked sleep fragmentation due to arousals from sleep. ${ }^{5}$

\section{Pathophysiology}

Instability of respiratory control underpins the development of Cheyne-Stokes respiration and results from hyperventilation, prolonged circulation time, and reduced blood gas buffering capacity. ${ }^{21}$

HYPERVENTILATION

Hyperventilation, the common pathophysiological feature of all forms of periodic breathing, causes $\mathrm{PaCO}_{2}$ levels to fall below the apnoeic threshold triggering a central apnoea. Once the peripheral chemoreceptors sense an apnoea related rise in the $\mathrm{PaCO}_{2}$ level above the apnoea threshold, hyperventilation recurs driving the $\mathrm{PaCO}_{2}$ level below the apnoea threshold

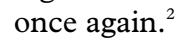

Increased central hypercapnic ventilatory responsiveness has been reported to occur in Cheyne-Stokes respiration with congestive heart failure ${ }^{22}$ and in other forms of periodic breathing in subjects without congestive heart failure-namely, idiopathic non-hypercapnic central sleep apnoea ${ }^{23}$ and high altitude periodic breathing. ${ }^{24}{ }^{25}$ A significant positive correlation between central hypercapnic ventilatory responsiveness and percentage sleep time with Cheyne-Stokes respiration has also been reported. ${ }^{26}$ Taken together, it would appear that Cheyne-Stokes respiration is associated with increased central chemosensitivity and explains the low mean $\mathrm{PaCO}_{2}$ observed during sleep and wakefulness in patients with CheyneStokes respiration. ${ }^{327}{ }^{28}$ As the response time of central chemoreceptors in normal subjects is of the magnitude of five minutes ${ }^{29}$ and the mean cycle length of Cheyne-Stokes respiration is 60 seconds, ${ }^{38} 30$ rapidly responsive peripheral chemoreceptors are likely to play an integral part in the propagation of Cheyne-Stokes respiration. ${ }^{29}$ Data in support of a significant positive relationship between increased peripheral chemosensitivity and periodic breathing, however, are limited to idiopathic nonhypercapnic central sleep apnoea ${ }^{23}$ and high altitude periodic breathing. ${ }^{24} 25$

It is likely that one or more of the following factors are likely to contribute to hyperventilation in congestive heart failure.

\section{Hypoxaemia}

Hypoxaemia may contribute to hyperventilation and Cheyne-Stokes respiration in congestive heart failure through peripheral chemoreceptor stimulation. However, in contrast to high altitude periodic breathing where hypobaric hypoxia stimulation of the peripheral chemoreceptors is likely to be responsible for the periodic breathing, ${ }^{24}$ hypoxia is thought not to be solely responsible for the development of Cheyne-Stokes respiration in patients with congestive heart failure for the following reasons. Hyperventilation, in the absence of 
hypoxaemia, has been shown to trigger central apnoeas during non-REM sleep induced by either mechanical hyperventilation in normal subjects $^{31}$ or by arousal induced hyperventilation in Cheyne-Stokes respiration ${ }^{3}$ and idiopathic non-hypercapnic central sleep apnoea. ${ }^{32}$ Furthermore, supplemental oxygen has been shown to attenuate rather than abolish Cheyne-Stokes respiration in patients with congestive heart failure. ${ }^{33-36}$

Increased pulmonary vagal afferent traffic

Increased pulmonary vagal afferent nerve traffic related to pulmonary venous congestion and pulmonary $\mathrm{C}$ fibre stimulation has been shown to induce rapid shallow breathing and hyperventilation in animal studies. ${ }^{37-40}$ In humans with congestive heart failure, those with Cheyne-Stokes respiration have a significantly greater pulmonary artery pressure (mean 34 $\mathrm{mm} \mathrm{Hg}$ ) than those without Cheyne-Stokes respiration (mean $21 \mathrm{~mm} \mathrm{Hg}$ ). ${ }^{6}$ Moreover, there is a significant inverse correlation between awake pulmonary capillary wedge pressure (PCWP) and awake $\mathrm{PaCO}_{2}{ }^{6}$ Finally, there is a tendency for the analogous condition high altitude periodic breathing to occur in patients with associated high altitude pulmonary oedema, ${ }^{41}$ so Cheyne-Stokes respiration with congestive heart failure is associated with increased pulmonary artery pressures, but whether this is a cause and effect relationship remains to be seen.

Increased sympathetic activity

Heistad et al reported a $20 \%$ increase in minute ventilation 10 minutes after a six minute venous infusion of noradrenaline, an effect that could be blocked by prior treatment with propranolol. ${ }^{13}$ As increased circulating noradrenaline levels and hyperventilation occur in congestive heart failure, ${ }^{11}{ }^{12}$ particularly in those with Cheyne-Stokes respiration, it is possible that peripheral chemoreceptors bathed in noradrenaline, or possibly central sympathetic activation related to spontaneous arousals, precipitates Cheyne-Stokes respiration. Upper airway collapse towards the end of the central apnoea, known to occur in Cheyne-Stokes respiration, ${ }^{42}$ may also cause arousal from sleep and thereby hyperventilation. ${ }^{3}{ }^{32}$

CIRCULATORY DELAY

The time taken for oxygenated blood leaving the pulmonary artery to reach the peripheral chemoreceptor, known as the circulation time, is increased in patients with congestive heart failure by virtue of a reduced cardiac output, increased cardiac chamber size, and increased circulating blood volume. However, circulatory delay in patients with congestive heart failure with mild Cheyne-Stokes respiration is similar to those with severe Cheyne-Stokes respiration (20.5 vs 25.0 seconds, respectively). ${ }^{3}$ Moreover, using canine models, artificial lengthening of the circulation times to as long as five minutes did not precipitate periodic breathing reliably. ${ }^{43}$ Hence, circulatory delay is thought not to be a significant precipitant of CheyneStokes respiration. However, circulatory delay is directly related to the length of the apnoea-hyperpnoea cycle and contributes to the crescendo-decrescendo respiratory pattern. $^{28} 30$

REDUCED BLOOD GAS BUFFERING CAPACITY

Reduced total body oxygen and carbon dioxide stores are considered factors that amplify the blood gas oscillations in Cheyne-Stokes respiration. Pulmonary function tests of patients with severe congestive heart failure reveal a restrictive ventilatory defect, and therefore oxygen storage, which relate to cardiomegaly and pleural effusions. ${ }^{44-46}$ Carbon monoxide transfer capacity is approximately $70 \%$ of predicted normal values in patients with severe congestive heart failure and correlates inversely with PCWP. ${ }^{46}$ Despite these findings, no significant differences in pulmonary function tests have been observed between those with and without Cheyne-Stokes respiration. ${ }^{39}{ }^{27}$ As patients with Cheyne-Stokes respiration hyperventilate awake and asleep, ${ }^{327}$ total body carbon dioxide stores are likely to be reduced, hence the carbon dioxide buffering capacity will be diminished.

\section{Treatment}

Generally, patients with Cheyne-Stokes respiration sufficient to cause symptoms have more than 20 apnoeas and hypopnoeas per hour sleep and should be considered for treatment. ${ }^{5}$ Treatment options can be broadly divided into five groups: intensive heart failure treatment, respiratory stimulants, respiratory depressants, oxygen, and continuous positive airway pressure (CPAP).

INTENSIVE HEART FAILURE TREATMENT

Although it would seem prudent to ensure that patients with Cheyne-Stokes respiration are on optimal medical treatment for congestive heart failure, and as a result the severity of Cheyne-Stokes respiration would diminish, there are only limited supportive data. In patients with congestive heart failure a raised PCWP is associated with greater mortality. ${ }^{47}$ Moreover, intensive medical treatment can reduce both PCWP and mortality in a subset of patients with severe congestive heart failure patients ${ }^{47}$ so, as patients with Cheyne-Stokes respiration have raised PCWP, one would expect the Cheyne-Stokes respiration in a subset of patients to diminish in severity with intensive medical therapy. Limited evidence in support is provided by a single small short term non-randomised study in which a 50\% reduction in the severity of Cheyne-Stokes respiration was observed with captopril over a four week period. ${ }^{48}$ Similar case series have reported reductions in Cheyne-Stokes respiration following intensive medical treatment, ${ }^{49} 50$ cardiac valve surgery, ${ }^{51}$ and cardiac transplantation, ${ }^{52}{ }^{53}$ but conversion of CheyneStokes respiration to obstructive sleep apnoea has also been reported following cardiac transplantation. ${ }^{54}$ 
RESPIRATORY STIMULANTS

Although respiratory stimulants (theophylline, carbon dioxide and acetazolamide) have been reported to reduce the severity of CheyneStokes respiration, they should be used with great caution. Javaheri et $a t^{55}$ reported a reduction in central apnoea and arousal frequency with five days theophylline treatment in 15 men with congestive heart failure for five days, although there was no significant improvement in cardiac function and quality of life data were not presented. Moreover, nocturnal supplemental oxygen therapy was also started without rationale at the same time as theophylline and placebo and was discontinued on the follow up sleep study. Theophylline and related drugs are well known for their arrhythmogenic ${ }^{56-58}$ and hyperventilation properties ${ }^{59}$ and thereby the requirements of cardiac output for respiratory muscles. ${ }^{20}$

Carbon dioxide inhalation has been shown to reduce the frequency of central apnoeas and hypopnoeas in patients with periodic breathing, ${ }^{60-64}$ but the chronic use of carbon dioxide inhalation as treatment for CheyneStokes respiration may not be feasible. In patients without congestive heart failure who demonstrate periodic breathing (idiopathic non-hypercapnic central sleep apnoea and high altitude periodic breathing), an increase of carbon dioxide levels via carbon dioxide inhalation, ${ }^{60-62}$ oxygen inhalation, ${ }^{64}$ or added dead space ${ }^{63}$ have resulted in stabilisation of respiration at the expense of increasing overall minute ventilation. ${ }^{64}$

The effects of other respiratory stimulants such as acetazolamide on Cheyne-Stokes respiration have not been systematically evaluated in patients with congestive heart failure. ${ }^{6566}$ Although reductions in central apnoea indices are reported with acetazolamide in the two available uncontrolled studies, both reported a significant fall in awake $\mathrm{PaCO}_{2}$ and an increase in hypercapnic ventilatory responsiveness indicating a greater degree of hyperventilation. ${ }^{65} 66$

Hence, at the present time there is little evidence in favour of the use of respiratory stimulants in Cheyne-Stokes respiration. Moreover, since patients with congestive heart failure who have Cheyne-Stokes respiration are already hyperventilating ${ }^{3}$ and have weak respiratory muscles ${ }^{67}$ there is no strong rationale for the use of these drugs in the chronic treatment of this disorder.

RESPIRATORY DEPRESSANTS

The effects of central nervous system respiratory depressants on Cheyne-Stokes respiration in patients with congestive heart failure have been tested in short term trials. The rationale for these trials was that suppression of arousability and ventilatory overshoot would prevent post-hyperventilatory apnoeas. Although various benzodiazepines did reduce the frequency of arousals, they failed to reduce the frequency of central apnoeas. ${ }^{68} 69$
OXYGEN

A number of studies have shown that the short term application of supplemental oxygen during sleep can attenuate Cheyne-Stokes respiration. ${ }^{33} 353648$ It is likely that oxygen reduces the peripheral chemoresponsiveness and allows $\mathrm{PaCO}_{2}$ levels to rise above the apnoea threshold ${ }^{64}$ Hanly et $a l^{33}$ observed a significant fall in Cheyne-Stokes respiration (30 to 19 events per hour) with treatment for a single night of $2-31 / \mathrm{min}$ intranasal oxygen in a randomised single blind study. Andreas et $a l^{35}$ reported a fall in Cheyne-Stokes respiration (26 to 10 events per hour) in 22 patients given 4 $1 /$ min intranasal oxygen for seven days in a randomised double blind crossover study. While on oxygen, patients also experienced a slight but statistically significant increase in peak oxygen consumption during exercise but no change in duration of exercise, peak heart rate, nor quality of life. ${ }^{35}$ Cardiac function has been found not to improve with six months oxygen treatment. ${ }^{34}$ Franklin reported that levels of up to $60 \%$ inspired oxygen were required to attenuate Cheyne-Stokes respiration. ${ }^{36}$ Longer term trials of oxygen to examine these issues in more detail are warranted. Gold et al have warned that central apnoeas may convert to mixed and obstructive apnoeas with supplemental oxygen. ${ }^{70}$

CONTINUOUS POSITIVE AIRWAY PRESSURE (CPAP) Considerable clinical evidence exists of beneficial short term effects of CPAP in acute cardiogenic pulmonary oedema ${ }^{71-78}$ and in stable congestive heart failure patients with PCWP > $12 \mathrm{~mm} \mathrm{Hg}{ }^{79}{ }^{80}$ an effect thought by some to be limited to patients in sinus rhythm. ${ }^{81}$ These clinical effects are thought to arise from a reduction in left ventricular afterload and heart rate (indicating reduced cardiac work) and assistance of inspiratory muscles, an increase in functional residual volume, improved ventilation perfusion matching, and reduced work of breathing. ${ }^{82-84}$ Abolition of upper airway obstruction and large subatmospheric pressures have been proposed as additional factors responsible for the longer term improvements in cardiac function reported particularly in subjects with obstructive sleep apnoea. $^{85-88}$

A before and after trial of CPAP at 8-12.5 $\mathrm{cm} \mathrm{H}_{2} \mathrm{O}$ applied at night for one month in five patients with Cheyne-Stokes respiration and congestive heart failure revealed a reduction in Cheyne-Stokes respiration and arousal frequency, an increase in nocturnal $\mathrm{SaO}_{2}$, and an improvement in symptoms and LVEF measured when awake (from $31 \%$ to $38 \%$ ). ${ }^{89}$ Thereafter, a randomised controlled study confirmed the findings in 24 patients over a three month period. ${ }^{5}$ CPAP was initiated at 5 $\mathrm{cm} \mathrm{H}_{2} \mathrm{O}$ and then increased to $10-12.5 \mathrm{~cm}$ $\mathrm{H}_{2} \mathrm{O}$ over 2-3 nights and used for an average of six hours at a pressure of at least $10 \mathrm{~cm} \mathrm{H}_{2} \mathrm{O}^{5}$ Additional findings were a reduction in overnight minute ventilation, a $6.4 \mathrm{~mm} \mathrm{Hg}$ rise in mean overnight transcutaneous $\mathrm{PCO}_{2}{ }^{90}$ associated with an increase in inspiratory muscle strength, ${ }^{91}$ suggesting that CPAP provided inspiratory assistance. Alleviation of 
Cheyne-Stokes respiration was most probably due to the rise in $\mathrm{PaCO}_{2}$ above the apnoea threshold secondary to the decrease in minute ventilation. Moreover, the rise in LVEF was associated with a reduction in mitral regurgitant fraction $^{92}$ and sympathetic activity, ${ }^{15}$ suggesting a remodelling of the left ventricle and improved cardiac efficiency. Improvements in LVEF and mitral regurgitation probably occurred secondary to increases in intrathoracic pressure which have been shown to reduce left ventricular afterload by decreasing left ventricle transmural pressure during systole, to which the failing heart is sensitive, and by reducing heart size. ${ }^{82} 93$ The mechanism of the fall in ventilation and increase in $\mathrm{PaCO}_{2}$ is likely to reflect an improvement in cardiac function, less pulmonary oedema, improved oxygenation, and lower circulating catecholamine levels.

There is controversy as to the effectiveness of CPAP for the treatment of congestive heart failure and Cheyne-Stokes respiration. Buckle et $a l^{94}$ found that application of CPAP of 5-7.5 $\mathrm{cm} \mathrm{H}_{2} \mathrm{O}$ for a single night did not affect the frequency of central apnoeas in eight patients with congestive heart failure and Cheyne-Stokes respiration. Guilleminault et $a l^{69}$ reported similar results with a one night application of CPAP. Davies et $a l^{95}$ studied the effects of CPAP of $5-7.5 \mathrm{~cm} \mathrm{H}_{2} \mathrm{O}$ over two weeks to a group of similar patients. Although full polysomnography was not performed on the follow up night, they concluded that CPAP had no effect on Cheyne-Stokes respiration. ${ }^{95}$ However, in none of these studies was cardiac function systematically assessed. Differences between these studies ${ }^{69} 9495$ and that of Naughton et $a \bar{l}$ are probably related to differences in the technique for initiating CPAP and in the study designs. ${ }^{96}$ In the studies from the other groups $^{69495}$ CPAP was not titrated over a period of several days, pressures used were lower, and the duration of treatment was much shorter than in the study of Naughton et al. ${ }^{5}$ Since it is well recognised that the beneficial cardiovascular effects of pharmacological afterload reducing agents such as angiotensin converting enzyme inhibitors require several months to be detected, and that they are dose related, ${ }^{97}$ the same is likely to be true of CPAP.

\section{Conclusion}

Patients with congestive heart failure and Cheyne-Stokes respiration have increased sympathetic activity, pulmonary vascular pressures, and greater mortality than patients without Cheyne-Stokes respiration. Whether identification of such patients and treatment alters prognosis remains to be determined. However, based upon current evidence, medical therapy directed at congestive heart failure, followed by CPAP (commenced gradually under supervision) and/or supplemental oxygen should be considered. The role of respiratory stimulants or suppressants in Cheyne-Stokes respiration needs further study.

1 Harrison TR, King CE, Calhoun JA, et al. Congestive heart failure. Cheyne-Stokes respiration as the cause of paroxysmal nocturnal dyspnea at the onset of sleep. Arch Intern Med 1934;53:891-910.
2 Bradley TD, Phillipson EA. Central sleep apnea. In: Phillipon EA Bradley TD, eds. Clinics in Chest Medicine son EA, Bradley TD, eds. Clinics in Chest

3 Naughton MT, Benard D, Tam A, et al. Role of hyperventilation in the pathogenesis of central sleep apneas in patients with congestive heart failure. Am Rev Respir Dis 1993;148: $330-8$.

4 Javaheri S, Parker TJ, Wexler L, et al. Occult sleepdisordered breathing in stable congestive heart failure. Ann Intern Med 1995;122:487-92.

5 Naughton MT, Liu PP, Benard DC, et al. Treatment of congestive heart failure and Cheyne-Stokes respiration during sleep by continuous positive airway pressure. Am $\mathcal{F}$ Respir Crit Care Med 1995;151:92-7.

6 Solin P, Roebuck T, Richardson M, et al. Comparison of awake pulmonary artery pressure and ventilation during sleep in congestive heart failure. Am f Respir Crit Care Med 1997;155:A868.

7 Smith WM. Epidemiology of congestive heart failure. $A m \mathcal{F}$ Cardiol 1985;55:3-8A.

8 Findley LJ, Zwillich CW, Ancoli-Israel S, et al. CheyneStokes breathing during sleep in patients with left ventricular heart failure. South Med $\mathcal{F}$ 1985;78:11-15.

9 Hanly PJ, Zuberi-Khokhar NS. Increased mortality associated with Cheyne-Stokes respiration in patients with congestive heart failure. Am $\mathcal{f}$ Respir Crit Care Med 1996;153:272-6

10 Andreas S, Hagenah G, Moller C, et al. Cheyne-Stokes respiration and prognosis in congestive heart failure. $A m \mathcal{F}$ Cardiol 1996;78:1260-4.

11 Cohn JN, Levine B, Olivari MT, et al. Plasma norepinephrine as a guide to prognosis in patients with chronic congestive heart failure. $N$ Engl F Med 1984;311:819-23.

12 Kaye DM, Lefkovits J, Jennings GL, et al. Adverse consequences of high sympathetic nervous activity in the consequences of high sympathetic nervous activity in the

13 Heistad DD, Wheeler RC, Mark AL, et al. Effects of adrenergic stimulation on ventilation in man. $\mathcal{F}$ Clin Invest 1972; 51:1469-75.

14 Cargill JI, Kiely DG, Lipworth BJ. Adverse effects of hypoxemia on diastolic filling in humans. Clin Sci 1995;89:165-9.

15 Naughton MT, Benard DC, Liu PP, et al. Effects of nasal CPAP on sympathetic activity in patients with heart failure and central sleep apnea. Am $\mathcal{f}$ Respir Crit Care Med 1995;152:473-9.

16 Cripps T, Rocker G, Stradling J. Nocturnal hypoxemia and arrhythmias in patients with impaired left ventricular funcarrhythmias in patients with impait
tion. Br Heart f 1992;68:382-6.

17 Davies SW, John LM, Wedzicha JA, et al. Overnight studies in severe chronic left heart failure: arrhythmias and oxygen desaturation. Br Heart f 1991;65:77-83.

18 Meridith IT, Broughton A, Jennings GL, et al. Evidence of a selective increase in cardiac sympathetic activity in patients with sustained ventricular arrhythmias. $N$ Engl $\mathcal{F} \mathrm{Med}$ 1991;325:618-24.

19 Mann DL, Kent RL, Parsons B, et al. Adrenergic effects on the biology of the adult mammalian cardiocyte. Circulation 1992;85:790-804.

20 Robertson CH, Pagel MA, Johnson RL. The distribution of blood flow, oxygen consumption, and work output among the respiratory muscles during unobstructed hyperventilation. f Clin Invest 1977;59:43-50.

21 Khoo MCK, Gottschalk A, Pack A. Sleep induced periodic breathing and apnea: a theoretical study. $\mathcal{F}$ Appl Physiol 1991;70:2014-24.

22 Wilcox I, Grunstein RR, Collins FL, et al. The role of central chemosensitivity in central sleep apnea of heart failure. Sleep 1993;16:S37-8.

23 Xie A, Rutherford R, Rankin F, et al. Hypocapnia and increased ventilatory responsiveness in patients with idiopathic central sleep apnea. Am $\mathcal{F}$ Respir Crit Care Med 1995;152:1950-5.

24 White DP, Gleeson K, Pickett CK, et al. Altitude acclimatisation: influence on periodic breathing and chemoresponsiveness during sleep. f Appl Physiol 1987;63:40112 .

25 Chapman KR, Bruce EN, Gothe B, et al. Possible mechanisms of periodic breathing during sleep. $\mathcal{F} A p p l$ Physiol 1988;64:1000-8.

26 Andreas S, von Breska B, Kopp E, et al. Periodic respiration in patients with heart failure. Clin Invest 1993;71:281-5.

27 Hanly PJ, Zuberi N, Gray R. Pathogenesis of Cheyne-Stokes respiration in patients with congestive heart failure. Relationship with $\mathrm{CO}_{2}$. Chest 1993;104:1079-84.

28 Hall MJ, Xie A, Rutherford R, et al. Cycle length of periodic breathing in patients with and without heart failure. $A m \mathcal{F}$ Respir Crit Care Med 1996;154:376-81.

29 Duffin J. The chemoreflex control of breathing and its measurement. Can f Anaesth 1990;37:933-42.

30 Solin P, Roebuck T, Swieca J, et al. Effects of cardiac dysfunction upon non-hypercapnic central sleep apnea. Chest 1998;113:104-10.

31 Datta AK, Shea SA, Horner RL, et al. The influence of induced hypocapnic and sleep on the endogenous respiratory rhythm in humans. F Physiol 1991;440:17-33.

32 Xie A, Wong B, Phillipson EA, et al. Interaction of hyperventilation and arousals in the pathogenesis of idiopathic central sleep apnea. Am f Respir Crit Care Med 1994;250:489-95.

33 Hanly PJ, Millar TW, Steljes DG, et al. The effect of oxygen on respiration and sleep in patients with congestive heart failure. Ann Intern Med 1989;111:777-82. 
34 Braghiroli A, De Vito F, Sacco C, et al. Six months oxygen therapy in patients with congestive heart failure: prelimitherapy in patients with congestive heart failure:

35 Andreas S, Clemens C, Sandholzer H, et al. Improvement of exercise capacity with treatment of Cheyne-Stokes respiration in patients with congestive heart failure. $\mathcal{F} \mathrm{Am} \mathrm{Coll}$ Cardiol 1996;27:1486-90

36 Franklin KA, Eriksson P, Sahlin C, et al. Reversal of central sleep apnea with oxygen. Chest 1997;111:163-9.

37 Churchill ER, Cope O. The rapid and shallow breathing resulting from pulmonary congestion and edema. 7 Exp Med 1929;49:531-7.

38 Paintal AS. Mechanisms of stimulation of type J pulmonary receptors. F Physiol (Lond) 1969;203:511-32.

39 Roberts AM, Bhattacharya J, Schultz HD, et al. Stimulation of pulmonary vagal afferent C-fibres by lung edema in dogs. Circ Res 1986;58:512-22.

40 Sackner MA, Kreiger BP. Noninvasive respiratory monitoring. In: Scharf SM, Cassidy SS, eds. Heart and lung interac tions in health and disease, Vol 42. New York: Dekker, 1991 663-805

41 Eichenberger U, Weiss E, Reimann, et al. Nocturnal periodic breathing and the development of acute high altitude illness. Am J Respir Crit Care Med 1996;154:1748-54.

42 Alex CG, Onal E, Lopata M. Upper airway occlusion during sleep in patients with Cheyne-Stokes respiration. Am Rev Respir Dis 1986;133:42-5.

43 Guyton AC, Crowell JW, Moore JW. Basic oscillating mechanisms of Cheyne-Stokes breathing. Am $\mathcal{F}$ Physio 1956;187:395-8.

44 Hosenpud JD, Stilbolt TA, Atwal K, et al. Abnormal pulmonary function specifically related to congestive heart failure: comparison of patients before and after cardiac transplantation. Am f Med 1990;88:493-6.

45 Light RW, George RB. Serial pulmonary function in patients with acute heart failure. Arch Intern Med 1983;143:429-33.

46 Naum CC, Sciurba FC, Rogers RM. Pulmonary function abnormalities in chronic severe cardiomyopathy preceding cardiac transplantation. Am Rev Respir Dis 1992;145: 1334-8.

47 Stevenson LW, Couper G Natterson B, et al. Target heart failure populations for newer therapies. Circulation 1995; 92(Suppl II):II-174-II-181.

48 Walsh JT, Andrews R, Starling R, et al. Effects of captopril and oxygen on sleep apnoea in patients with mild to moderate congestive heart failure. Br Heart $\mathcal{f}$ 1995;73:237-41.

49 Baylor P, Tayloe D, Owen D, et al. Cardiac failure presenting as sleep apnea. Elimination of apnea following medical as sleep apnea. Elimination of apnea following medic

50 Dark DS, Pingleton SK, Kerby GR, et al. Breathing pattern abnormalities and arterial desaturation during sleep in the congestive heart failure syndrome. Improvement following medical therapy. Chest 1987;91:833-6.

51 Tomcsany J, Karlocai K, Papp L. Disappearance of periodic breathing after heart operations. F Thorac Cardiovasc Surg 1994;107:317-8.

52 Murdock DK, Lawless CE, Loeb HS, et al. The effect of heart transplantation on Cheyne-Stokes respiration associated with congestive heart failure. F Heart Transplant 1986; 5:336-7.

53 Braver HM, Brandes WC, Kubiet MA, et al. Effect of cardiac transplantation on Cheyne-Stokes respiration occuring during sleep. Am 7 Cardiol 1995;76:632-4

54 Collop NA. Cheyne-Stokes ventilation converting to obstructive sleep apnoea following heart transplantation. Chest 1993;104:1288-9.

55 Javaheri S, Parker TJ, Wexler L, et al. Effect of theophylline on sleep disordered breathing in heart failure. $N$ Engl $\mathscr{F} \mathrm{Med}$ 1996;335:562-7.

56 Sessler CN, Cohen MD. Cardiac arrhythmias during theophylline toxicity: a prospective continuous electrocardiographic study. Chest 1990;98:672-8.

57 Bittar G, Friedman HS. The arrhythmogenicity of theophylline: a multivariate analysis of clinical determinants. Chest 1991;99:1415-20.

58 Packer M, Carver JR, Rodeheffer RJ, et al. Effect of oral milrinone on mortality in severe chronic heart failure. $N$ Engl 7 Med 1991;325:1468-75.

59 Dowell AR, Heyman A, Sieker HO, et al. Effect of aminophylline on respiratory-centre sensitivity in CheyneStokes respiration and in pulmonary emphysema. $N$ Englf Med 1965;273:1447-53.

60 Steens RD, Millar TW, Xiaoling S, et al. Effect of inhaled $3 \% \mathrm{CO}_{2}$ on Cheyne-Stokes respiration in congestive heart failure. Sleep 1994;17:61-8.

61 Villiger PM, Hess CW. Beneficial effect of inhaled $\mathrm{CO}_{2}$ in a patient with non-obstructive sleep apnoea. $\mathcal{f}$ Neurol 1993;241:45-8.

62 Badr MS, Grossman JE, Weber SA. Treatment of refractory sleep apnea with supplemental carbon dioxide. Am f Respi Crit Care Med 1994;150:561-4.

63 Xie A, Rankin F, Rutherford R, et al. Effects of inhaled CO and added dead space on idiopathic central sleep apnea. $\mathscr{F}$ Appl Physiol 1997;82:918-26.

64 Berssenbrugge A, Dempsey J, Iber C, et al. Mechanisms of hypoxia-induced periodic breathing during sleep in huhypoxia-induced periodic breathing
mans. F Physiol 1983;343:507-24.

65 White DP, Zwillich CW, Pickett CK, et al. Central sleep apnea. Improvement with acetazolamide therapy. Arch Intern Med 1982;142:1816-9.

66 DeBacker WA, Verbraeken J, Willemen M, et al. Central apnea index decreases after prolonged treatment with acetazolamide. Am $\mathcal{F}$ Respir Crit Care Med 1995;151:87-91.
67 McParland C, Krishnan B, Wang Y, et al. Inspiratory muscle weakness and dyspnea in chronic heart failure. Am Rev Respir Dis 1992;146:467-72.

68 Biberdorf DJ, Steens R, Millar TW, et al. Benzodiazepines in congestive heart failure: effects of temazepam on arousability and Cheyne-Stokes respiration. Sleep 1993;16:529-38 69 Guilleminault C, Clerk A, Labanowski M, et al. Cardiac failure and benzodiazepines. Sleep 1993;16:524-8.

70 Gold AR, Bleeker ER, Smith PL. A shift from central and mixed sleep apnea to obstructive sleep apnea resulting from low-flow oxygen. Am Rev Respir Dis 1985;132:220-3.

71 Emerson H. Artificial respiration in the treatment of edema of the lungs. Arch Intern Med 1909;iii:368-71.

72 Barringer TB. Pulmonary edema treated by artificial respiration. Arch Intern Med 1909;iii:372-3.

73 Poulton EP. Left sided heart failure with pulmonary oedema. Lancet 1936;981-983.

74 Barach AL, Martin J, Eckman M. Positive pressure respiration and its treatment of acute pulmonary edema. Ann Intern Med 1938;12:754-95.

75 Grace MP, Greenbaum DM. Cardiac performance in response to PEEP in patients with cardiac function. Crit Care Med 1982;10:358-60.

76 Rasanen J, Heikkila J, Downs J, et al. Continuous positive airway pressure by face mask in acute cardiogenic pulmonary edema. Am f Cardiol 1985;55:296-300.

77 Bersten AD, Holt AW, Vedig A, et al. Treatment of severe cardiogenic pulmonary edema with continuous positive airway pressure delivered by a face mask. $N$ Engl f Med 1991;325:1825-30.

78 Baratz DM, Westbrook PR, Shah PK, et al. Effect of continuous positive airway pressure on cardiac output and nts with congestive heart failure. Chest 1992;102:1397-407.

79 Bradley TD, Holloway RM, McLaughlin PR, et al. Cardiac output response to continuous positive airway pressure in congestive heart failure. Am Rev Respir Dis 1992;145:37782 .

80 De Hoyos A, Liu PP, Benard DC, et al. Haemodynamic effects of continuous positive airway pressure in humans with normal and impaired left ventricular function. Clin Sci 1995;88: $173-8$.

81 Liston R, Deegan PC, McCreery C, et al. Haemodynamic effects of nasal continuous positive airway pressure in
severe congestive heart failure. Eur Respir $\mathcal{F} 1995 ; 8: 430-5$.

82 Naughton MT, Rahman MA, Hara K, et al. Cardio-thoracic effects of continuous positive airway pressure in patients with heart failure. Circulation 1995;91:1725-31.

83 Naughton MT, Bookman I, Floras JS, et al. Effect of CPAP on respiratory mechanics in heart failure. Am f Respir Crit Care Med 1995;151:A706.

84 Lenique F, Habis M, Lafaso F, et al. Ventilatory and hemodynamic effects of continuous positive airway pressure in left heart failure. Am f Respir Crit Care Med 1997;155:5005.

85 Scharf SM, Bianco JA, Tow DE, et al. The effects of large negative intrathoracic pressure on left ventricular function in patients with coronary artery disease. Circulation 1981;63:871-5.

86 Tolle FA, Judy WV, Yu PL, et al. Reduced stroke volume related to pleural pressure in obstructive sleep apnea. $\mathcal{F}$ Appl Physiol 1983;55:1718-24.

87 Malone S, Liu PP, Holloway R, et al. Obstructive sleep apnoea in patients with dilated cardiomyopathy: effects of continuous positive airway pressure. Lancet 1991;338: 1480-4.

88 Krieger J, Grucker D, Sforza E, et al. Left ventricular ejection fraction in obstructive sleep apnea. Effects of long erm treatment with nasal continuous positive airway pressure. Chest 1991;100:917-21.

89 Takasaki Y, Orr D, Popkin J, et al. Effect of nasal continuous positive airway pressure on sleep apnea in con

90 Naughton MT, Benard DC, Rutherford R, et al. Effect of continuous positive airway pressure on central sleep apnea and nocturnal $\mathrm{PCO}_{2}$ in heart failure. Am 7 Respir Crit Care and nocturnal $\mathrm{PCO}_{2}$ in heart

91 Granton JT, Naughton MT, Benard DC, et al. Continuous positive airway pressure improves inspiratory muscle strength in patients with heart failure and Cheyne-Stokes respiration during sleep. Am $\mathcal{f}$ Respir Crit Care Med

92 Tkacova R, Liu PP, Naughton MT, et al. Effect of continuous positive airway pressure on mitral regurgitation and atrial natriuretic peptide in patients with heart failure and central sleep apnea. F Am Coll Cardiol 1997;30:739-45.

93 Fewell JE, Abendschein DR, Carlson CJ, et al. Continuous positive pressure ventilation decreases right and left 46:125-32.

94 Buckle P, Millar T, Kryger M. The effect of short term nasal CPAP on Cheyne-Stokes respiration in congestive heart failure. Chest 1992;102:31-5.

95 Davies RJO, Harrington KJ, Ormerod OJM, et al. Nasal continuous positive airway pressure in chronic heart failure with sleep disordered breathing. Am Rev Respir Dis 1993; 147:630-4.

96 Benard D, Naughton MT, Bradley TD. Administration of nasal continuous positive airway pressure to patients with congestive heart failure and Cheyne-Stokes respiration. $\mathcal{f}$ Polysomnographic Technol 1992;December:9-11.

97 The SOLVD Investigators. Effects of enalapril on survival in patients with reduced left ventricular ejection fractions and congestive heart failure. N Engl f Med 1991;325:293-302. 